\title{
Nonlinear Effects of Superstar Collaboration: Why the Beatles Succeeded but Broke Up
}

\author{
Tadashi Yagi ${ }^{1}$ \\ ${ }^{1}$ Faculty of Economics, Doshisha University, Kyoto, Japan \\ Correspondence: Tadashi Yagi, Faculty of Economics, Doshisha University, Imadegawa karasumi, Kamigyo, Kyoto, \\ 602-8580, Japan
}

Received: April 2, 2015

Accepted: April 20, 2015

Available online: April 21, 2015

doi:10.11114/aef.v2i2.783

URL: http://dx.doi.org/10.11114/aef.v2i2.783

\begin{abstract}
This paper examines the knowledge creation process that takes place in a group of superstar innovators. How does a superstar innovator influence the generation of knowledge in a team? In particular, does the effect increase nonlinearly as the number of talented team members increases? We explore these questions by considering the success and subsequent breakup of the Beatles, one of the most popular music groups in history. Through a mathematical analysis for exploring the fundamental mechanism of the breakup and its implications for superstar collaborations, we show that the breakup was an inevitable consequence of the superstar collaboration.
\end{abstract}

Keywords: Superstar collaboration, Beatles, knowledge, bread up, dynamic optimization

\section{Introducation}

Studies on the knowledge creation process are becoming increasingly important in regard to the creative economy, where new marketable knowledge and concepts are the key drivers of value creation and innovation. To date, much of the research in this field has focused on knowledge management and its effects on innovation, but the creative process is treated largely as a black box. Levin and Stephan (1991) empirically examine research motivations and show that the investment motive model is more effective than the consumption motive model in explaining the pattern of life-cycle research activities. Weitzman (1998) establishes the micro-foundations of knowledge creation, finding that the process entails not so much generating new ideas, as recombining an abundance of old ideas into a new usable form. Jones (2009) investigates recent trends in technological progress by considering the increasing educational burden on innovators, suggesting that increasing difficulty of innovation hinders long-run economic growth.

In the framework of knowledge creation, how are new ideas created within a team? Wuchty, Jones, and Uzzi (2007) point out the benefits of freely sharing knowledge through collaboration, and Mas and Moretti (2009) empirically study the strength of the peer effect within a group, showing that the productivity of an individual worker affects the productivity of co-workers, even for low-skilled workers. Bercovitza and Feldman (2011) investigate the composition of creative teams of academic scientists engaged in inventive activity, and find evidence of benefits due to knowledge diversity, particularly in the cases of truly novel combinations. Oettle (2013) develop the mechanisms by which scientists influence the productivity of others.

Azoulay, Zivin, and Wang (2010) estimate the magnitude of spillovers generated by academic "superstars". The idea in this paper is similar: to examine the knowledge creation process that takes place in a group of superstar innovators. How does a superstar innovator influence the generation of knowledge in a team? More specifically, does the effect of their influence increase nonlinearly as the number of talented team members increases? We explore these questions by considering the success and subsequent breakup of the Beatles, one of the most popular music groups in history.

Of the four musicians in the Beatles-John Lennon, Paul McCartney, George Harrison, and Ringo Starr-Lennon has a reputation for being innovative, socially conscious, and knowledgeable of aesthetics; McCartney is known for his innovative and joyous approach to music; Harrison is regarded as the quiet and philosophical Beatle with a strong sense of aesthetics; and Starr is known as the skillful, innovative, good-natured drummer of the band. With four distinct and complementary personalities brought together in a creative and synergistic alliance, the Beatles quickly found success and made music that was distinguished for being innovative, joyful, appealing, and diverse. 
Two other talented collaborators contributed to the success of the Beatles. Producer George Martin played a leading role in creating the distinct sound of the band by overseeing the group's musical arrangements, and the band's manager Bryan Epstein (who died in 1967) had a keen aptitude for promotion. By examining the way the Beatles created their music, we aim to examine whether a nonlinear effect of superstar collaboration is generated, and if so, how the effect comes about; moreover, we seek to elucidate the conditions for successful superstar collaboration.

In considering the nonlinear effect of collaboration in the Beatles, we cannot ignore the fact that the Beatles broke up only eight years after releasing their debut record. While there have been many theories regarding the breakup of the band, this paper focuses on the fundamental mechanism of the breakup and its implications for superstar collaborations. We show that the breakup was an inevitable consequence of the superstar collaboration. We present results of an analysis using a mathematical model to examine when collaboration becomes no longer beneficial for individual members of the Beatles, and show that the breakup of a superstar collaboration is a logical consequence of the knowledge creation process.

This paper is organized as follows. Section 2 describes the knowledge creation process of the Beatles, illustrating the nonlinear effects of superstar collaboration. Section 3 presents a mathematical model for capturing the breakup mechanism of superstar collaborations. Section 4 discusses the implications of the findings for the knowledge creation process in general.

\section{Knowledge Creation Process of the Beatles}

This section describes the knowledge creation process of the Beatles and illustrates the nonlinear effects of collaboration between talented music artists. For this purpose, we focus on cases of co-creation documented in journals, books, and videos.

\subsection{Definition of Nonlinearity}

The quality of music created by the Beatles is described by several factors (denoted by $e_{i}$ ) such as aesthetics, social consciousness, innovativeness, joyfulness, philosophical degree, harmoniousness, and variety. The linear characteristic equation of the co-creation process is defined as

$$
Q\left(\lambda e_{1}, \lambda e_{2}, \lambda e_{3}, \ldots, \lambda e_{n}\right)=\lambda Q\left(e_{1}, e_{2}, e_{3}, \ldots, e_{n}\right),
$$

where $Q$ is the quality of music created. If the quality function is specified by the linear combination of elements.

$$
Q\left(e_{1}, e_{2}, e_{3}, \ldots, e_{n}\right)=a_{0}+a_{1} e_{1}+a_{2} e_{2}+a_{3} e_{3}, \ldots, a_{n} e_{n},
$$

the quality of music will increase linearly as the number of talented artists in the group increases.

On the other hand, the nonlinear characteristic equation of co-creation process is defined as

$$
Q\left(\lambda e_{1}, \lambda e_{2}, \lambda e_{3}, \ldots, \lambda e_{n}\right)=\lambda^{t} Q\left(e_{1}, e_{2}, e_{3}, \ldots, e_{n}\right), t>1 .
$$

One example of a specification that exhibits nonlinear characteristics is multiple combination of quality elements:

$$
Q\left(e_{1}, e_{2}, e_{3}, \ldots, e_{n}\right)=\prod_{i=1}^{n} a_{i} e_{i} .
$$

The analysis aims to ascertain whether the quality of music increases nonlinearly as the number of talented artists in the group increases.

\subsection{Understanding Nonlinearity}

Before examining the knowledge creation process, it is important to have an intuitive understanding of nonlinearity. Connolly and Krueger (2006) and Strobl and Tucker (2000) argue that there is a skewed distribution of revenue from album sales. This is in line with the "superstar effect" proposed by Rosen (1981). In other words, the sales revenue differs drastically among music groups; a linear correlation between album sales and album quality implies that the quality of albums differs drastically among recording artists. Notably, there is strong evidence showing that nonlinear effects arise from the collaboration of superstar innovators as seen from the sales revenue generated by the Beatles as a group and generated by individual Beatles members after the band split.

According to the website Statistic Brain, as of April 16, 2013, the estimated total number of albums sold by the Beatles is 2.3 billion. Online encyclopedia Wikipedia estimates the total number of albums sold by McCartney and Lennon as 
solo artists to be around 100 million and 14 million, respectively. These figures suggest strong nonlinear effects arising from superstar collaboration in the band.

Table 1. Album Sales of the Beatles

\begin{tabular}{lc}
\hline & Data \\
\hline Total album sales statistics & $2,303,500,000$ \\
Total albums sold & 585,000 \\
$\quad$ Total albums sold on iTunes & 2.8 million \\
Total singles sold on iTunes & 1,278 weeks \\
Billboard chart statistics & 15 \\
$\quad$ Total weeks on chart & 175 weeks \\
Total number ones & 30 weeks \\
Total weeks at number one & \\
Album with longest time spent at number one & \\
(Please Please Me $)$ &
\end{tabular}

Source: http://www.statisticbrain.com/the-beatles-total-album-sales/.

Note: As of April 16, 2013. Statistics are from the Recording Industry Association of America, Apple Records, EMI. Date verified is July 23, 2012.

The nonlinear quality improvement in the quality of the Beatles' music can be attributed to several factors. Foremost, the appeal of the band lies in the evolution of the group's musical compositions. With each new album produced in an unprecedented lyrical and musical style, the Beatles created music in a way that resembled the making of art. A good example is the eclectic Abbey Road, a bestselling album that brings together elements of rhythm and blues, pop, soul, and rock and roll. By experimenting with new tunes and musical arrangements, the band improved on the sound and quality of its music. This would not have been possible if the band were not made up of talented artists successfully collaborating with one another.

By contrast, during the early years of the Beatles when Starr had yet to join the band, the sound of the group was characterized by a relatively lower quality (The Beatles Anthology, 1995). This was during the period from 1956 to 1962 when Pete Best, who was widely thought to be less talented than Starr, was still the drummer of the band. The implication is that artists whose skills are not on par with their group members can adversely affect the quality of the team output.

This is also evidence revealing the nonlinear properties of knowledge creation. Based on (4), we can write the following:

$$
Q\left(e_{1}, e_{2}, e_{3}, . ., 0, . ., e_{n}\right)=\prod_{i=1}^{n} a_{i} e_{i}=0
$$

The equation shows that with the presence of a subpar element, the overall quality of music created is severely affected, even reduced to zero in the extreme case.

\subsection{Creative Process of the Beatles}

This section will examine the creative process that superstar innovators engage in. There is no doubt that the Beatles were a group of extraordinarily talented musicians. Collaboration was key to the band's success. For instance, Lennon and McCartney were writing partners and co-wrote most of the band's bestselling hits ${ }^{1}$. In the recording studio, the four band members, together with Martin, regularly exchanged ideas and worked on enhancing the quality of their songs. This is evident based on footage in The Beatles Anthology (1995). The liner notes from the Beatles' album Sgt. Pepper's Lonely Hearts Club Band (1995) also provides revealing insights into the recording sessions of the band:

The Beatles' musical ideas progressed in a most tangible way with each album they recorded. Geoff Emerick, the recording engineer who with George Martin formed the imaginative team which translated the Beatles' requirements onto tape, once totted up the number of hours put into the making of Sgt. Pepper and came up with 700. Please Please Me, the Beatles' first album, was recorded in 585 minutes.

"The Beatles insisted that everything on Sgt. Pepper had to be different," says Emerick, "so everything was either distorted, limited, heavily compressed or treated with excessive equalization. We had microphones right down the bells of the brass instruments and headphones turned into microphones attached to violins. We plastered vast amounts of echo onto vocals, and sent them through the circuitry of the revolving Leslie speaker inside a Hammond organ. We used giant primitive oscillators to vary the speed of instruments and vocals and we had tapes chopped to pieces and stuck together upside down and the wrong way round." (Sgt. Pepper's Lonely Hearts Club Band 1995, p 1.) 
The creative process that went into the making of the Beatles' songs was not without challenges. According to Emerick and Massey (2006) and Lewisohn (1988), more than 70 takes were required in order to record a single song. For example, in recording "Ob-la-di Ob-la-da" from The Beatles (a.k.a. The White Album), Lennon played the song's piano part countless times until McCartney was satisfied with it.

No doubt, the caliber and talent of each band member has a direct bearing on the quality of music produced by the group. Bands made up of individually talented artists are more likely to produce better music as a result of the regular exchange of ideas within the group. Former Apple CEO Steve Jobs was reportedly impressed with the perfectionism of the Beatles after listening to a bootlegged recording of the many takes of "Strawberry Fields Forever" (Isaacson, 2011). Indeed, talented artists are also more likely to spot issues and engage in problem solving, which would improve the quality of music created.

Another factor key to successful creative collaboration in a team is the need for equal member status. Take for example a band with a chief songwriter who has a dominant position within the group. In such a band, the less dominant members are unlikely to comment on aspects relating to musical composition. Consequently, the caliber of the songwriter becomes the determining factor of the quality of music produced by the band. The implication is that the positive collaborative effect in the band becomes greatly weakened, and that the quality of the music might not be markedly improved during the recording sessions.

Hence the quality of the knowledge creation process of a group is determined by the degree of idea exchange and competition within the group. Music groups made up of members of unequal status easily foster rivalry. On the other hand, bands with members who have relatively equal status form highly creative and productive teams. These bands thrive on a free exchange of ideas, resulting in the nonlinear effects of superstar collaboration.

This point is described by the following formulation. Suppose that the quality of music be represented by

$$
Q\left(e_{1}, e_{2}, e_{3}\right)=A\left(p\left(e_{1} ; h\right) e_{1}\right)^{\alpha} e_{2}^{\beta} e_{3}^{\gamma},
$$

where $e_{1}$ is innovativeness, $e_{2}$ is joyfulness, $e_{3}$ is philosophical degree, $\alpha$ the weight of innovativeness in producing quality music, $\beta$ is the weight of joyfulness, and $\gamma$ is the weight of philosophical degree. Let $p\left(e_{1} ; h\right)$ be the probability of success in innovation depending on the level of competitiveness between members within the group, $h$. The nonlinear effects of superstar collaboration emerge when there is mutual cooperation in a group, increasing the probability of successful innovation. Lennon stated in an interview that he strived to create fundamentally innovative music during the Sgt. Pepper's Lonely Heart Club Band recording session in response to the creative efforts of McCartney and Harrison (Dig, 2010). A particular challenge was the innovative use of dissonance. The success of the innovative masterpiece "I Am the Walrus" on the album Magical Mystery Tour is a result of striving to include dissonance in the composition.

\subsection{The Breakup of the Beatles}

The Beatles had a critical year in 1967. Lennon met Yoko Ono, an avant-garde artist who was widely believed to be the catalyst leading to the split of the band. While the appearance of Ono was not the main reason that caused the breakup of the Beatles, the reasons why Lennon needed Ono and Harrison needed Indian philosophy were quite important. ${ }^{2}$ That year also marked the time when Lennon began to take an interest in the avant-garde movement. ${ }^{3} \mathrm{He}$ would soon incorporate avant-garde elements into the music of the Beatles for the band's next album. "Revolution 9" from The White Album was an experimental sound collage and shows Lennon's style diverging from that of the other Beatles. Meanwhile, behind the scenes in the recording studios, trouble was brewing for the Beatles. In another round of footage from The Beatles Anthology (1995), Martin noted that there was much unhappiness among the band members during the making of the album Let It Be, and the worsening relationships among the band members is evident in the film Let It $B e$.

As the four musicians began to explore different musical directions, the positive synergistic effects of collaboration in the Beatles began to fade. ${ }^{4}$ At the same time, there was a change in the power dynamics of the band. McCartney began taking on an increasingly dominant role in the Beatles, a factor which also catalyzed the split of the band, along with Harrison's complaint of unequal treatment.

It is worth discussing the financial factors that contributed to the Beatles' breakup, in addition to the factors related with the efficiency of knowledge creation. Unlike in many bands that had come previously, Lennon and McCartney's income from songwriting seemed to affect many of their decisions as performers. The financial necessity of playing at concerts was eliminated. Joint songwriting credit brought Lennon and McCartney into conflicts related to royalties from songwriting. These conflicts later developed into full-fledged lawsuits, damaging their friendship.

The following section explores the breakup of the Beatles by using a mathematical model. 


\section{The Breakup of the Beatles as a Knowledge Creation Model}

3.1 Dynamics of knowledge accumulation

Earlier in the paper, there is an analysis of the factors resulting in the nonlinear effects of superstar collaboration. In this section, the breakup of the Beatles will be analyzed using a knowledge creation model.

Let $k_{i e}(t)$ denote the knowledge stock of individual $i$ at time $t$. For this case study, $e$ may represent joyousness, estheticism, social consciousness, philosophical degree and innovativeness. The talent of an artist is a function of his or her knowledge accumulation. As human capital matures, knowledge creation within the group decreases for two reasons: decreasing differences in knowledge levels among members and reduced flexibility in accepting differences of knowledge creation. The knowledge accumulation function can be written as

$$
\frac{d k}{d t}=f\left(k_{i}\right) \phi\left(\alpha \sum_{j \in M} d\left(k_{i}-k_{j}\right)\right)+g\left(k_{i}\right) \phi\left((1-\alpha) \sum_{j \notin M} d\left(k_{i}-k_{j}\right)\right) .
$$

Here, $f$ represents the degree of flexibility in accepting differences of knowledge creation and is a decreasing function of $k$, and $\phi$ is an increasing function. Let $g$ be the knowledge creation which arises from collaborating with a non-member, assuming that it is an increasing function of $k$. Let $k_{i}(t)$ denote the vector of knowledge of member $i$ at time $t$ and let $\alpha(t)$ denote the portion of time spent with the member of the group.

\subsection{Optimal time allocation}

The members control the portion of time they spend working together so as to maximize their creative output in terms of quality, subject to the dynamic equation of knowledge capital $k$. The objective function is represented by (8) and the dynamic equation of knowledge is shown by (9). Assume the time discount rate is zero, with equal weight given to each period of time so as to simplify the model:

$$
\begin{aligned}
& \operatorname{Max}_{\alpha} \int_{t}^{T} Q\left(k_{i}(t): k_{j}(t)\right) d t \\
& \text { s.t. } \frac{d k}{d t}=f\left(k_{i}\right) \phi\left(\alpha \sum_{j \in M} d\left(k_{i}-k_{j}\right)\right)+g\left(k_{i}\right) \phi\left((1-\alpha) \sum_{j \notin M} d\left(k_{i}-k_{j}\right)\right)
\end{aligned}
$$

Hamiltonian for this problem is given by the following equation:

$$
H=Q\left(k_{i}(t)\right)+\lambda\left[f\left(k_{i}\right) \phi\left(\alpha \sum_{j \in M} d\left(k_{i}-k_{j}\right)\right)+g\left(k_{i}\right) \phi\left((1-\alpha) \sum_{j \notin M} d\left(k_{i}-k_{j}\right)\right)\right]
$$

The optimality conditions are given by (11) and (12), as follows:

$$
\begin{aligned}
& \frac{\partial H}{\partial \alpha}=\lambda\left[f\left(k_{i}\right) \phi^{\prime}\left(\alpha \sum_{j \in M} d\left(k_{i}-k_{j}\right)\right) \llbracket\left(\sum_{j \in M} d\left(k_{i}-k_{j}\right)\right)\right. \\
& \left.-g\left(k_{i}\right) \phi^{\prime}\left((1-\alpha) \sum_{j \notin M} d\left(k_{i}-k_{j}\right)\right) \llbracket\left(\sum_{j \notin M} d\left(k_{i}-k_{j}\right)\right)\right]=0 \\
& \frac{d \lambda}{d t}=-\frac{\partial H}{\partial k_{i}}=-\frac{\partial Q}{\partial k_{i}}-\lambda\left[f^{\prime}\left(k_{i}\right) \phi\left(\alpha \sum_{j \in M} d\left(k_{i}-k_{j}\right)\right)+f\left(k_{i}\right) \phi\left(\alpha \sum_{j \in M} d^{\prime}\left(k_{i}-k_{j}\right)\right)\right. \\
& \left.+g^{\prime}\left(k_{i}\right) \phi\left((1-\alpha) \sum_{j \notin M} d\left(k_{i}-k_{j}\right)\right)+g\left(k_{i}\right) \phi\left((1-\alpha) \sum_{j \notin M} d^{\prime}\left(k_{i}-k_{j}\right)\right)\right]
\end{aligned}
$$

The transversality condition is:

$$
\lim _{x \rightarrow T} \lambda(t) k(t)=0 .
$$

As long as $\lambda$ is positive, the optimality condition (11) implies that the optimal time share $\alpha$ is determined at the point where the following equation is satisfied:

$$
\begin{aligned}
& f\left(k_{i}\right) \phi^{\prime}\left(\alpha \sum_{j \in M} d\left(k_{i}-k_{j}\right)\right) \llbracket\left(\sum_{j \in M} d\left(k_{i}-k_{j}\right)\right) \\
& =g\left(k_{i}\right) \phi^{\prime}\left((1-\alpha) \sum_{j \notin M} d\left(k_{i}-k_{j}\right)\right) \llbracket\left(\sum_{j \notin M} d\left(k_{i}-k_{j}\right)\right)
\end{aligned}
$$


Since $\phi^{\prime}$ is a decreasing function, the left-hand side of the equation is a decreasing function of $\alpha$ while the right-hand side is an increasing function of $\alpha$. The left-hand side can be considered the marginal productivity of within-group knowledge creation (MPI) and the right-hand side measures the marginal productivity of outside group knowledge creation (MPO). Note the relationship between $k_{i}$ and the optimal level of $\alpha$. To illustrate this, we take the first derivative of the left- and right-hand sides with respect to $k_{i}$. The first derivative of the left-hand side is given by

$$
\begin{aligned}
& \frac{\partial f\left(k_{i}\right) \phi^{\prime}\left(\alpha \sum_{j \in M} d\left(k_{i}-k_{j}\right)\right) \llbracket\left(\sum_{j \in M} d\left(k_{i}-k_{j}\right)\right)}{\partial k_{i}}=f^{\prime}\left(k_{i}\right) \phi^{\prime}\left(\alpha \sum_{j \in M} d\left(k_{i}-k_{j}\right)\right) \llbracket\left(\sum_{j \in M} d\left(k_{i}-k_{j}\right)\right) \\
& +f\left(k_{i}\right) \phi^{\prime \prime}\left(\alpha \sum_{j \in M} d\left(k_{i}-k_{j}\right)\right) \llbracket \alpha \sum_{j \in M} d^{\prime}\left(k_{i}-k_{j}\right) \llbracket\left(\sum_{j \in M} d\left(k_{i}-k_{j}\right)\right) \\
& +f\left(k_{i}\right) \phi^{\prime}\left(\alpha \sum_{j \in M} d\left(k_{i}-k_{j}\right)\right) \llbracket\left(\sum_{j \in M} d^{\prime}\left(k_{i}-k_{j}\right)\right) .
\end{aligned}
$$

The derivative of the right-hand side with respect to $k_{i}$ is

$$
\begin{aligned}
& \frac{\partial g\left(k_{i}\right) \phi^{\prime}\left((1-\alpha) \sum_{j \notin M} d\left(k_{i}-k_{j}\right)\right) \square\left(\sum_{j \notin M} d\left(k_{i}-k_{j}\right)\right)}{\partial k_{i}}= \\
& g^{\prime}\left(k_{i}\right) \phi^{\prime}\left((1-\alpha) \sum_{j \notin M} d\left(k_{i}-k_{j}\right)\right) \square\left(\sum_{j \notin M} d\left(k_{i}-k_{j}\right)\right) \\
& +g\left(k_{i}\right) \phi^{\prime \prime}\left((1-\alpha) \sum_{j \notin M} d\left(k_{i}-k_{j}\right)\right) \square(1-\alpha) \sum_{j \notin M} d^{\prime}\left(k_{i}-k_{j}\right) \llbracket\left(\sum_{j \notin M} d\left(k_{i}-k_{j}\right)\right) \\
& +g\left(k_{i}\right) \phi^{\prime}\left((1-\alpha) \sum_{j \notin M} d\left(k_{i}-k_{j}\right)\right) \llbracket\left(\sum_{j \notin M} d^{\prime}\left(k_{i}-k_{j}\right)\right) .
\end{aligned}
$$

Because $f$ is a decreasing function of $k_{i}$ and $g$ is an increasing function of $k_{i}$, the MPO curves shift upward as $k_{i}$ increases, while MPI decreases as $k_{i}$ increases as shown in Figure 1. Therefore, one can conclude that the amount of optimal time spent collaborating within the group decreases. This suggests that the Beatles broke up as the knowledge stock of its members rose.

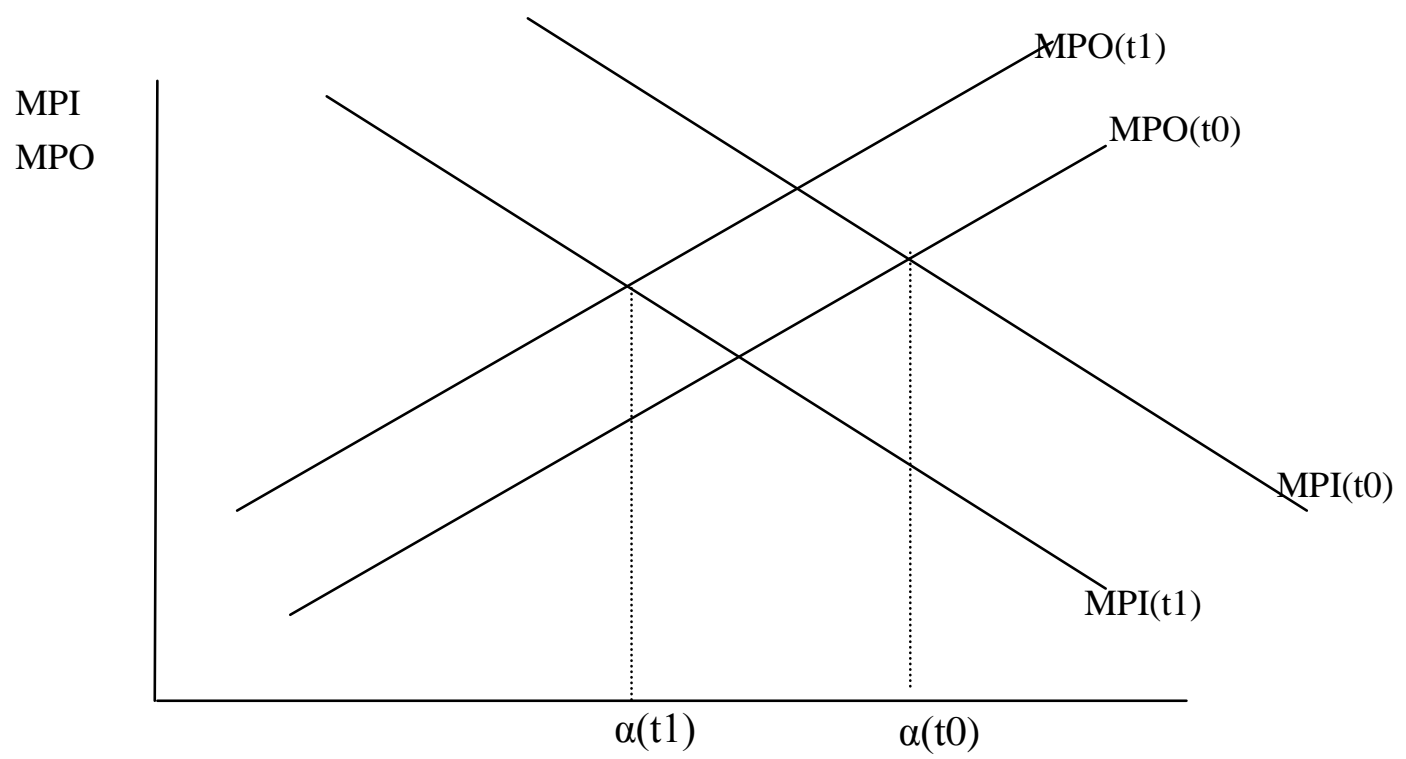

Figure 1. Value of co-creation within and outside the group 


\subsection{Implication of the Result}

The intuitive explanation for the analysis is as follows. As is shown in equation (7), knowledge creation is promoted by collaboration with a member with a different knowledge set. When the Beatles started their activities, each member could give new knowledge to each of the other members; therefore, all members stimulated one another. By absorbing different knowledge from the other members, the Beatles could accumulate their knowledge capital in the early stage of the group's activities. In this stage, they had little incentive to collaborate with non-members due to the high cost of associating with an unfamiliar collaborator. However, the benefits of collaborating within the group decrease as the proportion of common knowledge increases, as depicted by the downward shift of the MPI curve in Figure 1.

As the proportion of common knowledge among members increases, the efficiency of knowledge creation also decreases because of a corresponding decrease in the amount that members can learn from one another. Yet, at the same time, the benefits of collaborating with non-members increase because the gap in knowledge increases as each member's knowledge capital increases. This mechanism is reflected in the upward shift of the MPO curve. From these reasons, the optimal portion of the time spent for collaboration with non-members increases.

Combined with (6), the optimality conditions imply that the quality of music produced by the group is as follows:

$$
Q=Q\left(A\left(p\left(e_{1}\left(k_{1}\left(\alpha_{1}\right), . ., k_{4}\left(\alpha_{4}\right)\right) ; h\right) e_{1}\left(k_{1}\left(\alpha_{1}\right), . ., k_{4}\left(\alpha_{4}\right)\right)\right)^{\alpha} e_{2}^{\beta}\left(k_{1}\left(\alpha_{1}\right), . ., k_{4}\left(\alpha_{4}\right)\right) e_{3}^{\gamma}\left(k_{1}\left(\alpha_{1}\right), . ., k_{4}\left(\alpha_{4}\right)\right)\right.
$$

Based on this equation, one can finally understand why the final album recorded by the Beatles, Abbey Road, is critically acclaimed as a masterpiece, even though it was recorded when the group was on the verge of breaking up: the period during which the album was recorded coincided with the creative peak of each member of the band. As opposed to the recording of Let It Be, which was made at a time marked by tense relations between the band members, the production of Abbey Road saw the Beatles successfully work as a team. Although many people regard the album as a "McCartney production" rather than a truly collaborative effort, side two in particular contains elements of the essential Beatles teamwork. For example, upon examining "Come Together" by Lennon, it becomes clear that McCartney's bass in Abbey Road significantly increases the artistic value of the album. In "I Want You (She's So Heavy)" as well, McCartney's bass brings out the potential of Lennon's composition, elevating the song to a masterpiece. It is similarly clear that Starr could not have produced "Octopus's Garden” without receiving assistance from Harrison.

Finally, we would like to discuss about the post-breakup evolution of each member's music. As is predicted by the model, the music of each member developed through receiving stimulus from various artists. After the breakup, Lennon created his masterpiece "Imagine" which was inspired by Ono's exhibition where objects were cut in half to stimulate the imagination of the missing portion. Lennon later produced Mind Game, Walls and Bridges, and finally Double Fantasy after a five-year hiatus. Except for last album released during his lifetime, Double Fantasy, Lennon's post-breakup work was not as commercially successful as his work with the Beatles, although the artistic value of his music has been lauded by many critics. McCartney is still active and continues to go on worldwide concert tours. However, it is worth noting that McCartney himself admits that the quality of music he produced during his 7 years as a member of the Beatles is superior to what he has produced in the 43 years after the breakup. This is reflected in the set lists of his concerts, of which over $60 \%$ is music originally performed by the Beatles. Interpreting this result in the context of our model, this indicates that a superstar collaboration has nonlinear effects during the knowledge creation process.

\section{Conclusion}

Taking up the case of the Beatles, this paper examined the knowledge creation process of superstar innovators and the nonlinear effects which arose from peer collaboration. Theoretical models usually simplify the structure of the mechanism at hand, and this simplification tends to ignore important factors that arise in the real world. The use of the Beatles' breakup as an example is valuable for deepening the understanding of the meaning and implications of the theoretical model. By combining anecdotes and historical accounts of the Beatles, it becomes possible to clarify the implications and the limitations of the theoretical model. This also contributes to understanding the essential reasons for the Beatles' breakup. 
An important implication of this work is that the incentives for collaborating within a team tend to decrease as the knowledge of each member is shared over time. The findings of this paper may be applied to the practice of human resource management in firms. Company executives may decide to employ the same personnel so as to maintain continuity of the company brand and image or increase the staff turnover as a way of inculcating a more competitive spirit in employees.

The paper also revealed the conditions conducive to successful innovation through collaboration. A harmonious environment in which team members can trade ideas freely and engage in fair play fosters creativity, leading to innovation. This finding will be useful to businesses for planning the organizational structure of the company's research and development division. In particular, the study will be useful for businesses in deciding on a flat or hierarchical structure for the research team. It is implied that overly strong initiative on the part of an individual team member in the research and development process possibly deteriorates the collaboration effect among researchers.

Lastly, the analysis illustrated the importance of diversity during the process of knowledge creation. The nonlinear effects of superstar collaboration emerge in a team made up of talented individuals who each possesses a unique specialist knowledge or expertise. By putting to use the diverse sets of skills and knowledge, talented innovators can achieve successful innovation in a team, and the value of the innovation and new knowledge increases nonlinearly as the talent of members of the team increases.

\section{Acknowledgements}

I appreciate the precious comments from the anonymous referees. This work was supported by JSPS KAKENHI grant number 24330092, and in part by a grant of Strategic Research Foundation Grant-aided Project for Private Universities from Ministry of Education, Culture, Sport, Science, and Technology, Japan (MEXT), 2013-2017 (S1391010).

\section{References}

Azoulay, P., Joshua, S., Graff, Z., \& Jialan, W. (2010). Superstar Extinction, The Quarterly Journal of Economics, 125, 549-589. http://dx.doi.org/10.1162/qjec.2010.125.2.549.

Bercovitza, J., \& Maryann, F. (2011). The Mechanisms of Collaboration in Inventive Teams: Composition, Social Networks, \& Geography, Research Policy, 40, 81-93, http://dx.doi.org/10.1016/j.respol.2010.09.008

Connolly, M., \& Alan, B. K. (2006). Rockonomics: The Economics of Popular Music. In Handbook of the Economics of Art and Culture, edited by Victor A. Ginsburg, and David Throsby, 667-719. Amsterdam: Elsevier.

Emerick, G., Massey, H. (2006). Here, There and Everywhere: My Life Recording the Music of The Beatles. New York: Penguin Books.

Isaacson, W. (2011). Steve Jobs. New York: Simon and Schuster.

Jones, B. F. (2009). The Burden of Knowledge and the 'Death of the Renaissance Man': Is Innovation Getting Harder? Review of Economic Studies, 76, 283-17. http://dx.doi.org/ 10.1111/j.1467-937x.2008.00531.x

Levin, S. G., \& Paula, E. S. (1991). Research Productivity over the Life Cycle: Evidence for Academic Scientists, American Economic Review, 81, 114-132.

Lewisohn, Mark. (1988). The Beatles Recording Sessions. New York: Harmony Books.

Sgt. Pepper's Lonely Hearts Club Band. CD. (1995). Liner notes. London: Capitol Records.

Mas, A., \& Enrico, M. (2009). Peers at Work, American Economic Review, 99, 112-145. http://dx.doi.org/ 10.1257/aer.99.1.112

Oettl, A. (2013). Reconceptualizing Stars: Scientist Helpfulness and Peer Performance. Management Science, 58(6).1122-1140. http://dx.doi.org/10.1287/mnsc.1110.1470.

Rosen, S. (1981). The Economics of Superstars, The American Economic Review, 71, 845-858.

Statistic Brain. (2012). The Beatles, last modified July 23, http://www.statisticbrain.com/the-beatles-total-album-sales/.

Strobl, E. A., \& Clive, T. (2000). The Dynamics of Chart Success in the U.K. Pre-Recorded Popular Music Industry, Journal of Cultural Economics, 24, 113-134. http://dx.doi.org/10.1023/a:1007601402245.

Kevin-Godley, B. S., \& Geoff, W. (1995).The Beatles Anthology. DVD. Directed by London: Capitol Records.

Shinko Music Mook. (2010). THE DIG Special Edition John Lennon. [In Japanese.] Tokyo: Shinko Music Entertainment Co., Ltd. 
Weitzman, M. L. (1998). Recombinant Growth. Quarterly Journal of Economics, 113, 331-360.

Notes:

Note 1. In interview footage from The Beatles Anthology (1995), McCartney said he and Lennon composed songs together when on concert tours.

Note 2. Lennon's Imagine and Harrison's My Sweet Road are proof that Ono and Indian philosophy were important to them.

Note 3. Lennon said in an interview published in The Dig Special Edition that he did not agree with all of the tenets of the avant-garde movement. What he had wanted to do was create something similar to avant-garde art.

Note 4. The last album recorded by the Beatles, Abbey Road, was considered a masterpiece. It was also revealed in footage from The Beatles Anthology that the band members worked with each other in an atmosphere of positive collaboration during the making of the final album.

\section{(c) EY}

This work is licensed under a Creative Commons Attribution 3.0 License. 